\title{
Photochemical Study of Hydrated Ammonium Aluminum Sulfate-Urea Ionic Liquid by FT-IR Spectroscopy
}

\author{
Evon Akram \\ Department of Chemistry, College of Science, Al-Nahrain University, Baghdad-Iraq. \\ Corresponding Author: eve.jabar@yahoo.com.
}

\begin{abstract}
The stability of ionic liquid which makes it interest to study the photochemistry of hydrated ammonium aluminum sulfate $\left.\mathrm{NH}_{4} \mathrm{Al} \quad \mathrm{SO}_{4}\right)_{2} \cdot 12 \mathrm{H}_{2} \mathrm{O}$-urea $\left.\mathrm{CO} \mathrm{NH}_{2}\right)_{2}$ sample to show photo degradation rate by FTIR spectra effect with different times which indicated a few influence irradiation the ionic liquid with increase time that indication stability of ionic liquids green chemistry). [DOI: $10.22401 / \mathrm{JUNS} .21 .1 .0 \mathrm{~V}$ ]
\end{abstract}

Keywords: Ionic liquid, Photochemistry, FT-IR spectroscopy, Green chemistry.

\section{Introduction}

Infrared FT-IR spectroscopy is one of important the ancient that well determined experimental techniques. FT-IR spectroscopy is measuring the wavelength and the intensity of the absorption of its radiation by a sample. The most sensitive spectral the region of the urea structural components is the vibrational band $1600-1700 \mathrm{~cm}^{-1}$ ), which is almost consequent quite to the $\mathrm{C}=\mathrm{O}$ stretch vibration, $3300-3100 \mathrm{~cm}^{-1}$ ) the $\mathrm{N}-\mathrm{H}$ stretching and the C-N stretching vibration 1480-1575 $\left.\mathrm{cm}^{-1}\right)[1]$. While the vibrational bands of N-H 3460$3371 \mathrm{~cm}^{-1}$ ), $\mathrm{C}=\mathrm{O} 1647 \mathrm{~cm}^{-1}$ ) and $\mathrm{C}-\mathrm{N} 1462 \mathrm{~cm}^{-1}$ ) in hydrated ammonium aluminum sulfate-urea ionic liquid [2]. Green chemistry of ionic liquids are salts cation and anion part .These liquids exhibit very low vapor pressures, low melting points, thermal stabilities, environmentally friendly and their utility as solvents [3]. The inorganic photochemistry is presently experiencing a development. One of the few transition metal complexes are luminesces strongly in solution at room temperature with displays powerful photosentitisation capability to electron, energy, transfer operation. It is generating some vivid argumentation on the fundamental questions regarding the factors are govern the exhilarated of the state processes. The photochemistry and surfactant derivatives as well as studies in multiphase systems of monolayers, micelles, vesicles, polyelectrolytes, ieolites, cellulose etc) [4]. Ionic liquids are preferably suited to using as solvents in the photochemistry. A few reports on the photochemistry reactions are in ionic liquids. The photo isomerization is proceeding in 1-butyl-3 -methylimidazolium hexafluorophosphate $\left[\mathrm{bmim} \mathrm{PF}_{6}\right.$ ) and the rate much- larger than the prospective from itis polarity and viscosity1[5], Jones et al [6]. The reported photoreduction of benzophenone $\mathrm{BP})$ by the amines in the ionic liquids [7]. The photoelectron transfer from ruthenium II) tris bipyridyl) and methylviologen in [bmim] $\mathrm{PF}_{6}$, it was described by McLean et a $l[8]$. Ionic liquids were shown with a large range using to be compatible for the solvents in many types the photochemistry reactions. The results detected in some Ionic liquids evenly are different from its observed in ordinary the solvents [9-11]. This differences would be caused by the topical structure and many domains in the ionic liquids which have suggested lately by Hamaguchi et al [12], Nishikawa et al [13] and Wishart et al [14]. The experiments were inspected the ionic liquids 1-ethyl -3-methylimidazolium bis trifluoromethylsulfon yl)imide $\left[\mathrm{C}_{2} \mathrm{mim}\right]\left[\mathrm{NTf}_{2}\right]$ over the entire mixture range and the organic solvent is methanol which measured by FTIR spectroscopy in the mid-infrared region would be perfectly reproduced up XMeOD 0.5). The calculated intensities of the frequencies originate is from the mole fraction of the anion and cation of the ionic liquids with methanol molecules interacting and participatory with methanol hydrogen bonded chains its molecules. The formation of methanol bunch studied by the stretching vibrational bands that between 2300-2800 $\mathrm{cm}^{-1}$ ) [15]. 
Experimental Part

\section{A. Materials}

Hydrated ammonium aluminum sulfate $\left.\left.\left.\mathrm{NH}_{4} \mathrm{Al} \quad \mathrm{SO}_{4}\right)_{2} .12 \mathrm{H}_{2} \mathrm{O} \quad \mathrm{CO} \quad \mathrm{NH}_{2}\right)_{2} \mathrm{BDH}\right)$ and urea $\left[\mathrm{NH}_{2} \mathrm{CONH}_{2}\right]$ THOMAS BAKER) in a mole ratio of 1:5) were grind together respectively, well mixed and heated gradually to $85^{\circ} \mathrm{C}$ ) in a closed glass tube with gently continuous stirring even the solid salts changed to colorless liquid [2].

\section{B. Techniques}

The measuring system was applied a FTIR spectroscopy IR-Prestige-21: SHIMADZU, Travel-IR: Sens IR Technologies) [16] shown in Fig.1. The broad band infrared light is using meddlesome by the application of Michelson interferometer that sent to the sample. In the sample place is electing the best method by each sample with using the MCT Mercury Cadmium Tellurium) detector in IR fiber probe processing The employing the DLATGS Deuterated L-Alanine Triglycine Sulphate) detector in process. The absorption infrared interference light observe by the optical detector that shown on the PC an interferogram signal. This is signal transformed by Fourier transformation). We obtain the vertical axis is absorbance and the horizontal axis of spectrum is wavenumber. This measured spectrum were using data correction between 4000-500 $\mathrm{cm}^{-1}$ ) [17].

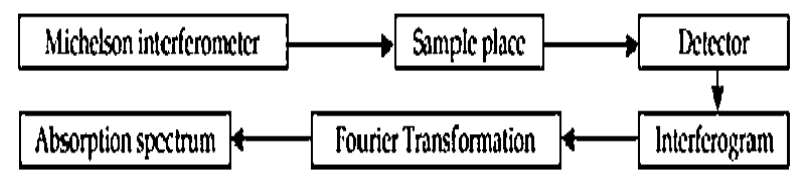

Fig.(1): The block diagram of measurement system.

\section{Results and Discussion}

Measuring the photodegradation rate of the ionic liquid hydrated ammonium aluminum sulfate $\mathrm{NH}_{4} \mathrm{Al}\left(\mathrm{SO}_{4}\right)_{2} \cdot 12 \mathrm{H}_{2} \mathrm{O}$-urea $\mathrm{CO}\left(\mathrm{NH}_{2}\right)_{2}$ sample that using infrared FTIR spectra this makes ionic liquid very interesting for researchers in the field of photochemistry. The absorption spectra of the ionic liquid was registered in the range of $\left(4000-500 \mathrm{~cm}^{-1}\right)$, however the suggestion for the photodecomposition process was following by the mechanism (Eq. (1-3)). The absorption of amine is specified at $\left(3400-3300 \mathrm{~cm}^{-1}\right)$ when the $\mathrm{N}-\mathrm{H}$ stretching vibrational bands of the urea amine group at $\left(3215 \mathrm{~cm}^{-1}\right)$ in ionic liquid which show in the FTIR measurement increase irradiation time with decreased intensity slowly shown in Table (1) Fig. (2). The $\mathrm{C}=\mathrm{O}_{\text {str }}$ band in ionic liquid at $\left(1666-1627 \mathrm{~cm}^{-1}\right)$ that absorption is specified at $\left(1722 \mathrm{~cm}^{-1}\right)$ and the $\mathrm{C}=\mathrm{O}_{\text {bend }}$ absorption in ionic liquids at $\left(1103 \mathrm{~cm}^{-1}\right)$ which is specified at $\left(1170 \mathrm{~cm}^{-1}\right)$, the intensity of bands changed clearly decreased shown in Table $(2,3)$ Fig. $(3,4)$, since the frequency of the vibrational band of urea is depending on the natural of hydrogen bonding that involving the $\mathrm{C}=\mathrm{O}$ with $\mathrm{NH}$ moieties therefore, this decrease indicates that a coordinate bond was formed between nitrogen and oxygen with the metal aluminum by donor the pairs of electrons on $\mathrm{C}=\mathrm{O}$ and $\mathrm{N}-\mathrm{H}$ with metal to formation ionic liquid and disappearance the resonance between this nitrogen atom and the carbonyl group. The C-Nstr vibrational bands at $\left(1550 \mathrm{~cm}^{-1}\right)$ and in ionic liquid at $\left(1384 \mathrm{~cm}^{-1}\right)$ shown in Table (4) Fig.(5) which can be assigned to the intensity decreased these changes were related to lower the energy of band influencing by irradiation times of FTIR it also indicated contribution the electron pair for amine and carbonyl in urea to formation ionic liquid. The vibrational modes of the Aluminum remained nearly constant shown in Table (5) Fig.(6) which was consistent in the anion of ionic liquid this indicated interaction aluminum metal with the electron pair of urea to formation ionic liquid. The photodegradation different irradiation times are following by observing the changes in $\left(\mathrm{N}-\mathrm{H}, \quad \mathrm{C}-\mathrm{O}_{\text {str }}, \quad \mathrm{C}-\mathrm{O}_{\text {bend }}, \quad \mathrm{C}-\mathrm{N}_{\text {str }}\right.$ and Aluminum) in the ionic liquids .The time changes could also be followed by FTIR absorption spectroscopy for ionic liquid indicating the cation part of ionic liquid which play a major role in the degradation process through noted the length of banding $\mathrm{N}-\mathrm{H}_{\text {str }}$ a few changes with increase time indicator for stability of ionic liquids which makes it real (green chemicals) and persistence in the environment. The method to calculated the irradiation times with length bands by band index method [18-20] which includes

Is $=\frac{A s}{A r}$ 
As=Absorbance of the peak under the study. Ar=Absorbance of the reference peak. Is=Index of the group under the study.

The percentage of transmittance $(\% \mathrm{~T})$ is changing into the absorbance (A) the using Berr-Lambent law in the following equation.

$\mathrm{A}=\log (100 T \%)$

$\mathrm{A}=\log 100-\log \% T$

$\mathrm{A}=2-\log T \%$

$\mathrm{A}=\mathrm{ATop}$ peak - ABase line

Table (1)

Irradiation times with length bands of $\mathrm{NH}_{\text {str }}$

\begin{tabular}{|c|c|}
\hline $\begin{array}{c}\text { Irradiation } \\
\text { Times (min) }\end{array}$ & $\begin{array}{c}\text { Length bands } \mathbf{N H}_{\text {str }} \\
\text { (cm) }\end{array}$ \\
\hline \hline 0 & 0.53 \\
\hline \hline 10 & 0.47 \\
\hline \hline 15 & 0.4 \\
\hline \hline 30 & 0.39 \\
\hline \hline 120 & 0.36 \\
\hline 160 & 0.3 \\
\hline
\end{tabular}

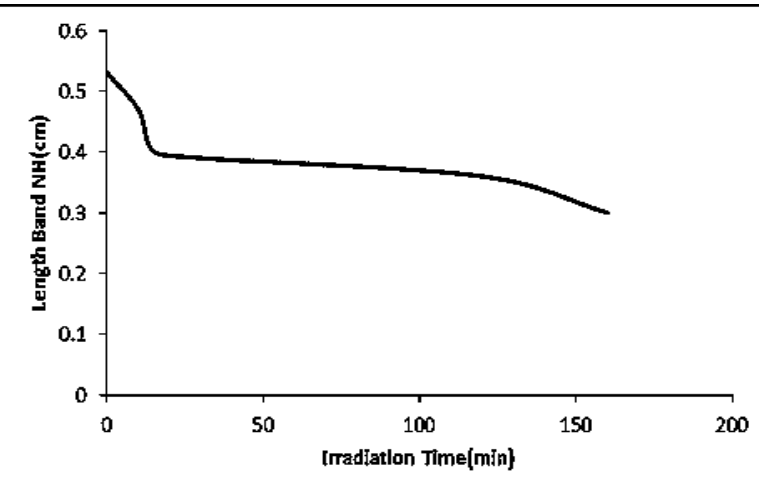

Fig.(2): The relation of length bands $\mathrm{NH}_{\text {str }}$ with irradiation times.

Table (2)

Irradiation times with length bands of $\mathrm{CO}_{\text {str. }}$.

\begin{tabular}{|c||c|}
\hline $\begin{array}{c}\text { Irradiation Time } \\
(\text { min })\end{array}$ & Length band CO $_{\text {str }}$ \\
\hline \hline 0 & 0.1 \\
\hline \hline 10 & 0.65 \\
\hline \hline 15 & 0.64 \\
\hline \hline 30 & 0.44 \\
\hline 120 & 0.47 \\
\hline \hline 160 & 0.44 \\
\hline
\end{tabular}

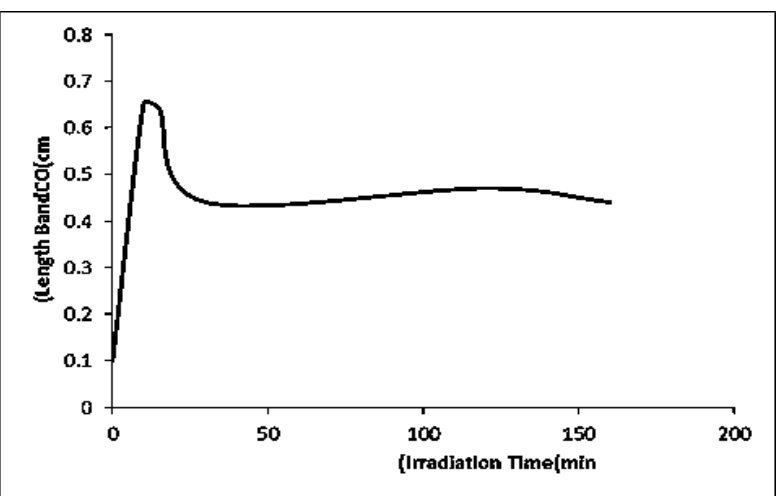

Fig.(3): The relation of length bands $\mathrm{CO}_{\text {str }}$ with irradiation times.

Table (3)

Irradiation times with length bands of $\mathrm{CO}_{\text {bend. }}$

\begin{tabular}{|c||c||}
\hline $\begin{array}{c}\text { Irradiation Time } \\
(\text { min })\end{array}$ & $\begin{array}{c}\text { Length band } \text { CO }_{\text {ben }} \\
(\mathbf{c m})\end{array}$ \\
\hline \hline 0 & 0.1 \\
\hline \hline 10 & 1 \\
\hline 15 & 0.78 \\
\hline 30 & 0.48 \\
\hline \hline 120 & 0.47 \\
\hline \hline 160 & 0.45 \\
\hline
\end{tabular}

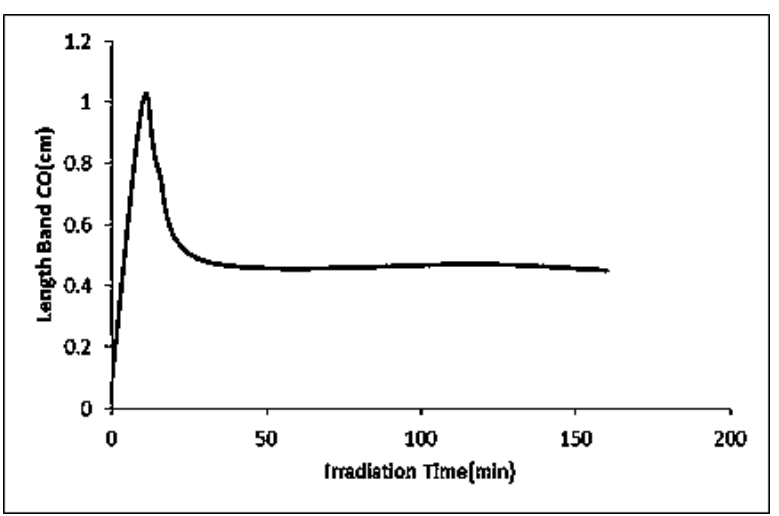

Fig.(4): The relation of length bands $\mathrm{CO}_{\text {bend }}$ with irradiation times.

Table (4)

Irradiation times with length bands of $\mathrm{CN}_{\text {str }}$.

\begin{tabular}{|c|c|}
\hline $\begin{array}{c}\text { Irradiation Time } \\
\text { (min) }\end{array}$ & $\begin{array}{c}\text { Length band } \boldsymbol{C N}_{\text {str }} \\
\text { (cm) }\end{array}$ \\
\hline \hline 0 & 0.83 \\
\hline \hline 10 & 0.91 \\
\hline \hline 15 & 0.71 \\
\hline \hline 30 & 0.4 \\
\hline \hline 120 & 0.47 \\
\hline \hline 160 & 0.57 \\
\hline
\end{tabular}




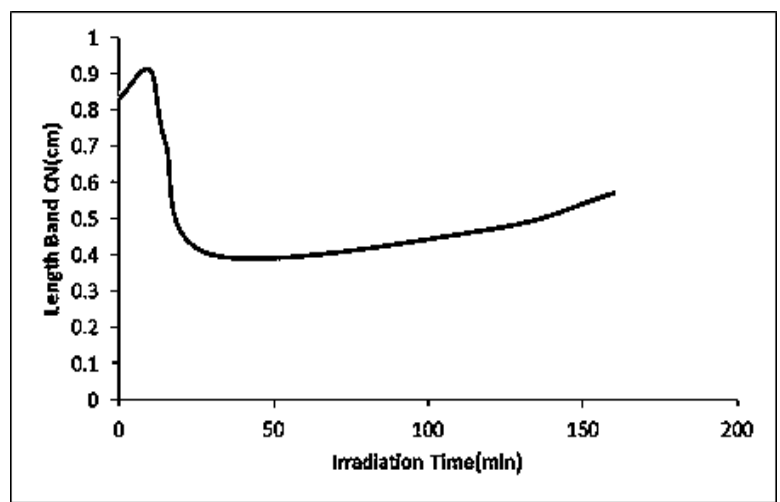

Fig. (5): The relation of length bands $C N_{s t r}$ with irradiation times.

Table (5)

Irradiation times with length bands of Aluminum.

\begin{tabular}{|c||c||}
\hline $\begin{array}{c}\text { Irradiation Time } \\
\text { (min) }\end{array}$ & $\begin{array}{c}\text { Length band } \\
\text { Aluminum }(\mathrm{cm})\end{array}$ \\
\hline \hline 0 & Not shown \\
\hline \hline 10 & 1.17 \\
\hline 15 & 1.23 \\
\hline 30 & 1.13 \\
\hline \hline 120 & 1.13 \\
\hline \hline 160 & 1.57 \\
\hline
\end{tabular}

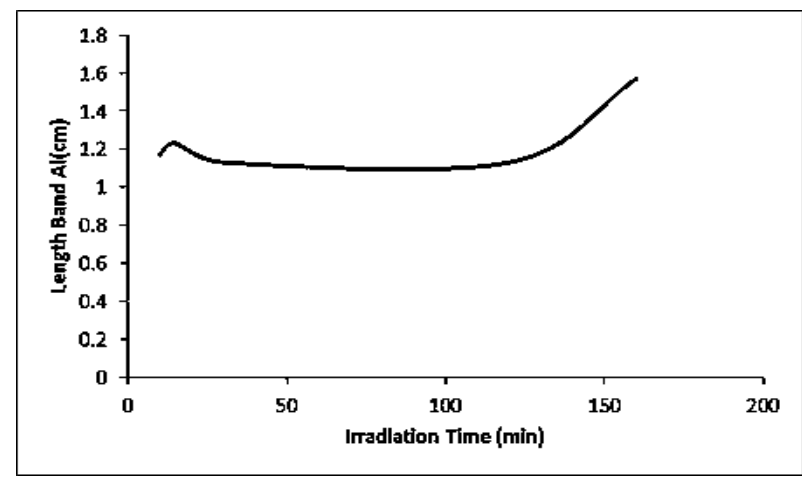

Fig.(6): The relation of length bands Aluminum with irradiation times.

\section{Conclusions}

We investigated the photochemistry of room temperature ionic liquid hydrated ammonium aluminum sulfate-urea $\mathrm{NH}_{4} \mathrm{Al}$ $\left(\mathrm{SO}_{4}\right)_{2} \cdot 12 \mathrm{H}_{2} \mathrm{O}-\mathrm{CO}\left(\mathrm{NH}_{2}\right)_{2}$ sample by using FT-IR spectroscopy to measuring the photo degradation rate which indicated decreasing the vibrational bands for $\left(\mathrm{NH}_{\text {str,bend }}, \mathrm{CO}_{\text {str,bend }}\right.$, $\mathrm{CN}_{\text {str }}$ ) and no clearly changes for aluminum metal this results are explained slightly effect on ionic liquid which considered environmentally.

\section{References}

[1] Kong J., Shaoning Y., "Fourier Transform Infrared Spectroscopic Analysis of Protein Secondary Structures", Journal of Acta Biochimica et Biophysica Sinica, (39), 549559, 2007.

[2] Al-Qudsi Z. Abood H., "The Electronic Transition Behavior Cr (III), Fe (III), Fe (II) and Ni (II), Transition Metal Cations In Ammonium Alum-Urea Room Temperature Ionic Liquid", Journal of Al-Nahrain University,(16), 46-55, 2013.

[3] Jonathan G. and John L., "Green Chemistry: Comparison of Ionic Liquid vs Conventional Solvent for Indole Alkylation", American Journal of Undergraduate Research, (13), 5-9, 2016.

[4] Kalyanasundaram K., "Photophysics, Photochemistry and Solar Energy Conversion with tris (bipyridyl) ruthenium (ii) and its Analogues", journal of Elsevier Scientific Publishing Company, (46), 159244, 1982.

[5] Wakasa M., "The Magnetic Field Effects on Photochemical Reactions in Ionic Liquids", Journal of Phys. Chem., (32), 338-8570, 2007.

[6] Ozawa R., Hamaguchi H., "Does Photoisomerization Proceed in an Ionic Liquid?" Journal of Chemical Society of Japan, (30), 736-737, 2001.

[7] John L., Kimberly R. and Paul B., "Photoreduction of Benzophenones by Amines in Room-Temperature Ionic Liquids", Journal of Organic Letters, (4), 917-9194, 2002 .

[8] Charles M. Andrew J., "Photoelectron transfer from excited-state ruthenium (II) tris (bipyridyl) to methylviologen in an ionic liquid", Journal of Chem. Commun, (10), 1395-1396, 2000.

[9] Mark J., Andrew J., Charles M. Gordon and Ian R. Dunkina, "Hydrogen abstraction from ionic liquids by benzophenone triplet excited states", Journal of Chem. Commun, (10), 2364-2365, 2001.

[10] Andrew J., Mark J., Charles M. Gordon and Ian R. Dunkinb, "Bimolecular rate constants for diffusion in ionic liquids", Journal of Chem. Commun, (10), 1880 1881, 2002. 
[11] Alvaro M., Ferrer B., Gracia H., Narayana M., "Screening of an ionic liquid as medium for photochemical reactions", Journal of Chemical. Physics, (10), 435440, 2002.

[12] Hamaguchi H,. Ozawa P., "Structure of ionic liquids and ionic liquid compounds: are ionic liquids genuine liquids in the conventional sense", Edited by Stuart A. Rice, (131), 85, 2005.

[13] Nishikawa K., Wang S., Katayanagi H., Hayashi S., Hamaguchi H., Koga Y. and Tozaki K., "Melting and Freezing Behaviors of Prototype Ionic Liquids, 1Butyl-3-methylimidazolium Bromide and Its Chloride, Studied by Using a Nano-Watt Differential Scanning Calorimeter", Journal of Chemical. Physics, (111), 4894-4900, 2007.

[14] Edward W. Castner, and James F. Wishart, "Spotlight on ionic liquids", Journal of Chemical. Physics, (111), 120901, 2010.

[15] Roth C., Appelhagen A., Jobst N., and Ludwig R., "Microheterogeneities in IonicLiquid-Methanol Solutions Studied by FTIR Spectroscopy, DFT Calculations and Molecular Dynamics Simulations", Journal of Chemical. Physics, (13), 1708-1717, 2012.

[16] Koyama S., Ishizawa H., Miyauchi Y. and Dozono T., "Introduction of Non-Invasive Measurement Method by Infrared Application", Journal of Intech, (405), 80102, 2012.

[17] Campus Z, Greece A., "Introduction to Infrared Spectroscopy" Journal of Intech, (405), 2-10, 2012

[18] Ali M., Gamal A. El-Hiti G., Ibraheem H., Yousif E., Investigation of the Photodecomposition Rate Constant of Poly (Vinyl Chloride) Films Containing Organotin (IV) Complexes, Journal of AlNahrain University, 20(3), 18-23, 2017.

[19] Awad A., Gamal A. Al-Hasani A., Yousif E., Study The Rate Constant of Photodecomposition of Polystyrene Films in Presence of Some 4-amino-5-(2-(6methoxynaphthalen-2-yl)piperidino)-1,2,4triazole-3-thion Complexes, Journal of AlNahrain University, 19(1), 69-75, 2016. 